\title{
Language learning and teaching - theory and practice
}

\section{Theory and principles}

\author{
90-265 Chambers, Angela ( $U$. of Ulster, N. Ireland). Foreign languages in \\ industry and commerce in Northern Ireland: a survey. NIMLA (Coleraine, N. Ireland). \\ 20/21 (1988/89), 1-10.
}

A survey was made by the University of Ulster of the role of foreign languages in industry and commerce in Northern Ireland, with particular reference to exporting. Small firms in Northern Ireland have been criticised for being too dependent on local markets instead of exporting. A questionnaire was sent to 111 companies known to be exporting to non-English-speaking countries. Some were not interested because their export sales are organised either from Great Britain or through an English-speaking agent in the country concerned, but it is felt that this places them at a disadvantage. A large proportion of exporting companies (44\%) have no knowledge of the languages spoken in the countries to which they export. The majority of textile and engineering companies have employees with some foreign language knowledge, but in the majority of food, drink and clothing companies employees have no such skills.

The vast majority of companies are aware of the importance of foreign-language skills. Textile companies had the highest level of awareness, closely followed by engineering companies. Almost half the respondents said they would be interested in language tuition, larger firms being more likely to send staff on a course than smaller ones. Intensive courses were the most popular. Grant aid has a major role to play in encouraging companies to improve their foreign-language skills.

The main languages required were German and French, then Arabic, Japanese and Chinese. There was little interest in learning Scandinavian languages or Dutch. Clothing companies were particularly interested in learning relevant languages (German, French and Italian). Textile companies were particularly interested in Italian.

The survey raises questions about whether it might be more beneficial to offer a diversity of language experience at school, rather than exclusive concentration on one language.

\section{0-266 Edge, Julian (U. of Birmingham). Ablocutionary value: on the application of language teaching to linguistics. Applied Linguistics (Oxford), 10, 4 (1989), 407-17.}

As far as English language teaching is concerned, applied linguistics may be seen to have grown out of a desire to liberate language teaching from an intellectual subservience to linguistics. Instead of involving itself in the co-operative creation of knowledge by linguists and language teachers, however, applied linguistics, in some of its manifestations, has set itself up as a barrier between the two, intent more on its own development as a discipline than on informed linguistic/pedagogic activity. The working relationship between language teaching and linguistics needs to be based on two-way communication and mutual respect, for valid conceptualisation and theorising is most likely to arise from informed activity and reflection. An example of a partial perspective on linguistic description arising from work in language teaching is offered for criticism.

90-267 Germain, Claude (U. of Quebec at Montreal). Un cadre conceptuel pour la didactique des langues. [A conceptual framework for language teaching.] Études de Linguistique Appliquée (Paris), 75 (1989), 61-77.

The need for a conceptual framework for the teaching of second or foreign languages is stressed and two models of 'educational linguistics' are examined and compared. Two schools of thought can be discerned in research in this area: one takes as its starting point what actually happens in the classroom, while the other begins with a number of psycholinguistic hypotheses concerning language and language acquisition. First and foremost there is the need to reconcile these two traditions. [In an appendix, the Community Method and the Natural Approach to language are contrasted and their implications for classroom teaching analysed.] 
90-268 Guberman, Solange (U. of Ottawa). Compétence linguistique et compétence de communication dans l'acquisition d'une langue seconde. [Linguistic competence and communicative competence in second language acquisition.] Rassegna Italiana di Linguistica Applicata (Rome), 21, 3 (1989), 49-60.

This survey of the development of linguistic theory and its reflection in language teaching shows the changes of emphasis from the study of the structure of the L2 through to the commusiicative approach and the parallel development from teacher-centred to student-centred techniques. However, the problem of whether a teacher should concentrate more on linguistic competence or on appropriate use of language has still not been resolved. It is still unclear how linguistic theory can help to resolve the dilemma of how an awareness of appropriacy in language can be incorporated into L2 learning. Although it seems to be instinctively understood that linguistic competence must come before communicative competence, much research remains to be done.

\section{0-269 Hecht, Karlheinz and Green, Peter S. Grammatische Kompetenz und Performanz. Ein Forschungsbericht. [Grammatical competence and performance: a research report.] Die Neueren Sprachen (Frankfurt am Main, FRG), 88, 6 (1989). 573-90.}

The article examines how competence in grammar is converted into performance. Three different kinds of tests were given to both native and non-native speakers of English to determine their respective levels of competence and performance: (1) the passive grammar test (multiple choice), (2) the productive grammar test (fill-in-the-blank), (3) the grammar in performance test (open-ended, communicative task). The three tests, all of which covered the same selection of grammatical items, were taken by 220 English pupils, 433 German middle-school pupils, and 358 German pupils in the advanced level of secondary school. The English pupils supplied the native-language frame of ref- erence, whilst the two groups of German pupils provided a basis for examining how performance and competence develop. The tests served to confirm or reject a number of hypotheses, the principal one being that pupils are for the most part able to convert their grammatical competence into performance in communicative tasks. The results show that, while German pupils do achieve a good level of competence, there is a wide discrepancy between competence and performance. It is suggested that this may be due to both the lack of sufficient opportunities for creative use of the foreign language in classroom discourse and the learning of rules that are not effective as language-processing tools.

\section{0-270 Jones, Sabine ( $U$. of Ulster. N. Ireland). Interaction of language and culture. NIMLA (Coleraine. N. Ireland), 20/21 (1988/89), 27-44.}

Culture is the outcome of the interaction and interpenctration of language, thought and social environment, and the relationship among the cultural components takes different forms in different cultures. Cultural variations as manifested in language behaviour occur on different levels; they occur on an intra-linguistic level between syntax, lexis and intonation, as well as between verbal and non-verbal behaviour; and when those linguistic and paralinguistic features are related to the whole of the sociocultural framework, differences in communication strategies are found which are based on different cultural attitudes and values.

In the communicative approach to language teaching the aim is no longer simply to teach students how to acquire linguistic competence (i.e. knowledge of linguistic systems and language structures), but also to acquire sociocultural competence, that is to develop a degree of sociocultural awareness and sensitivity in order to make an appropriate use of the target language and to accurately interpret foreign-language behaviour. For this purpose students need some strategies and devices which are based on a contrastive analysis comparing similar and dissimilar features of the home- and the target language.

The achievement of sociocultural competence may, however, be in conflict with a third and equally important aim in language teaching, which is the achievement of psycholinguistic competence; here the learner is encouraged to express his or her own personality when using the foreign language. A conflict may arise, because the learner is expected to do two different things at the same time, namely to express his or her own personality in the foreign language as well as to adapt to foreign cultural norms. Although the goal may be to emphasise all three forms of competence to the same degree (i.e. 
linguistic, sociocultural and psycholinguistic competence), teachers equally have to accept the learner's expectations and wishes, and in different classroom situations and with different learners they may have to make different compromises, ranging from cultural sensitisation to practical social skills training.

\section{0-271 Prabhu, N. S. Acquisition through comprehension: three procedures Focus on English (Madras, India), 5, 4 (1989), 1-12.}

The widely held notion that comprehensible input is the most effective means to language acquisition is challenged by a view which emphasises methods encouraging the process of comprehension, rather than the product of it. It is in the effort to comprehend the relations between structure and meaning that learners gain the most intensive exposure to a language. The teacher's task is accordingly threefold: to encourage and respond to efforts at comprehension, to adjust the levels of adequacy demanded on different occasions, and to expose learners to a variety of language structures in a range of contexts.
The adequacy of various approaches to language learning are considered in the light of the above criteria. Situational presentation, although one of the most popular of approaches to language learning, fails to fulfil any of the conditions. The largely neglected grammar-translation method, in giving precedence to comprehension over production, should be reconsidered; but it is problem-solving or task-based activity which meets all the criteria and thereby encourages the creation of optimum conditions for language learning.

90-272 van Essen, Arthur. Grammar: its place in foreign-language education. Der fremdsprachliche Unterricht (Stuttgart, FRG), 96 (1989), 4-10.

This article deals with meanings of the word 'grammar' and with changes in language teaching methodology since the eighteenth century. The word 'grammar' has been used to refer to theories describing language in general or individual languages, to shared or distinguishing features of languages, and to communicative competence.

Current emphasis is on communicative language teaching and the pragmatic or sociocultural rules which govern language use. These rules, however, appear infrequently in coursebooks, even though they are accepted as essential. The communicative use of language must take precedence over oldfashioned grammar teaching, which is once more regarded with some favour.

\section{Psychology of language learning}

\section{0-273 Bialystok, Ellen (York U., Canada). The dangers of dichotomy: a reply to Hulstijn. Applied Linguistics (Oxford), 11, 1 (1990), 46-51.}

Hulstijn [see abstract 90-283] has presented a comparison of two theoretical approaches to language learning which he labels 'information-processing' and 'Analysis/Control'. This paper is a reply to some of the issues he raises in that critique. The argument is that, by presenting the two theories dichotomously, he has obscured their fundamental similarity as information-processing theories and misrepresented details of both positions. A response to his discussion of the "Analysis/Control approach' is presented.

\section{0-274 Cameron, Judy and Epling, W. Frank (U. of Alberta). Successful} problem solving as a function of interaction style for non-native students of English. Applied Linguistics (Oxford), 10. 4 (1989), 392-406.

The present study investigated interaction styles and success at problem solving by students of English as a second language. Students were selected from a continuing education programme at Alberta Vocational Centre. These subjects were chosen on the basis of active or passive participation in the classroom. Following this selection, subjects were randomly assigned to Active-Active, ActivePassive, or Passive-Passive groups which were comprised of eight same-sex dyads. Each dyad was 
required to solve ten problems on a two-way interaction task. Results indicated that ActiveActive and Active-Passive pairs were equally successful at the task and both were superior to the Passive-Passive group. An analysis of those factors that may have contributed to task solution was conducted. It is argued that these results have practical importance for teaching English as a second language. One recommendation is that when teachers involve students in pair activities, passive students should be placed with active ones.

90-275 Carlisle, Robert S. (California State U., Bakersfield). The writing of Anglo and Hispanic elementary school students in bilingual, submersion, and regular programmes. Studies in Second Language Acquisition (Bloomington, Ind), 11, 3 (1989), 257-80.

The purpose of this descriptive cross-sectional study was to describe and rate the writing of Hispanic students in a bilingual programme and to compare their writing with that of Hispanic students in a submersion programme and with native English speakers in a regular programme. Five dependent variables were investigated: rhetorical effectiveness, overall quality of writing, productivity, syntactic maturity, and error frequency. Analyses of variance for both grade and programme revealed that the sixth graders had significantly higher scores than did the fourth graders on all of the dependent variables except for error frequency. The students in the regular programme had significantly higher scores on rhetorical effectiveness and overall quality of writing than did the submersion programme students and the bilingual programme students; they also made significantly fewer errors than did the bilingual programme students. The bilingual programme students had significantly higher scores on syntactic maturity and productivity than did the submersion programme students. Results suggest that students who learn to write in their L1 before learning to write in their L2 will write just as effectively in their L2 as those students who learn to write only in their L2.

90-276 Carroll, Susanne (Ontario Inst. for Studies in Ed.). Language acquisition studies and a feasible theory of grammar. Canadian Journal of Linguistics (Toronto). 34, 4 (1989), 399-418.

Language acquisition studies can provide values for a feasible theory of grammar; in particular they can lead to more specific proposals concerning what constitutes restricted data for acquiring a phenomenon $\mathrm{P}$, how long it ought to take to acquire it, what cognitive mechanisms can be posited and how powerful they must be. The author emphasises the difference between acquisition involving triggering and that which involves learning; the values proposed may vary considerably for each type. What constitutes restricted data for the triggering of gender assignment in first language (French) acquisition is insufficient data when it comes to learning French gender as a second language. Temporal values will change depending upon whether $\mathrm{P}$ involves triggering or skill development. Triggering may involve instantaneous acquisition or maturation, in which case acquisition will appear to take time but will in fact be instantaneous for the purposes of the theory of grammar. Learning will also involve temporal values but they will vary according to properties of the environment (frequency of exposure, order of learning etc.). Some triggered phenomena will be acquired when the learning mechanism is at an early cognitive/ biological stage while others will appear later in the maturational sequence. Some learning will make fewer demands on processing capacities and attention, require less knowledge of the world, etc., and will show up early in the learning sequence. Other types of phenomena will depend upon the maturation of the information-processor, or on greater or more varied experience (what might be called 'representational maturation').

Second-language acquisition studies can be particularly instructive, when coupled with studies of the primary acquisition of the same phenomenon, in that they provide appropriate variation for each category of value. Clearly, the proposals made here suggest a rather different way of interpreting acquisition data and will require careful exploration. Uninterpreted data cannot inform grammatical theory. Acquisition data must be embedded in an acquisition theory: developing such a theory is an enormous task. The feasibility approach advocated here will permit a limited use of acquisition data in grammatical argumentation in a way that is more likely to clarify grammar-internal issues than is currently possible. 
90-277 Crookes, Graham (U. of Hawaii, Manoa). Planning and interlanguage variation. Studies in Second Language Acquisition (Bloomington, Ind), 11, 4 (1989), 367-83.

Having focused previously on attention, cognitively oriented investigations of interlanguage variation and development are turning toward other possible explanatory variables, such as planning. The present study reports on an experiment in which two groups of 20 Japanese learners of English as a second language performed two monologic production tasks with and without time for planning. It was found that providing learners with time to plan their utterances results in interlanguage productions which are more complex in the short run.

90-278 Derwing. Tracey M. (U. of Alberta). Information type and its relation to non-native speaker comprehension. Language Learning (Ann Arbor, Mich), 39, 2 (1989), 157-72.

A native speaker/non-native speaker (NS/NNS) conversational adjustment in the relative proportions of information type was examined for its relation to communicative success. Sixteen native speakers of English were paired with other native speakers and with low-proficiency non-native speakers. The subjects viewed a short film, the content of which they were to relay to their two partners independently. Communicative success was measured through comprehension questions addressed to the listeners at the completion of the task. The relative importance of propositional information in the narratives was determined and adjustments were measured. Analyses indicated that an increase in the proportion of background detail correlated with comprehension problems for second-language learners. The implications of the findings are discussed and suggestions for further research are made.

90-279 Eckman, Fred R. and others ( $U$. of Wisconsin-Milwaukee). Implicational universals and interrogative structures in the interlanguage of ESL learners. Language Learning (Ann Arbor, Mich), 39. 2 (1989), 173-205.

The validity of two implicational universals regarding constituent order in questions is tested in the English speech of 14 native speakers of Japanese, Korean, and Turkish. The interlanguage evidence is found to be generally supportive of the two universals. Some fundamental methodological problems are discussed which are attendant upon testing universals not only in interlanguages but in linguistic systems of any kind.

\section{0-280 Ehrlich, Susan (York U.) and others. Discourse structure and the negotiation of comprehensible input. Studies in Second Language Acquisition (Bloomington, Ind), 11, 4 (1989), 397-414.}

This article examines the role of negotiations of meaning in providing comprehensible input for NNS (non-native speaker) learners. An experiment is reported which was conducted with NS-NNS and NS-NS pairs involving a picture-drawing task, where one member of each pair instructed the other in the drawing of simple objects. The results of the experiment suggest that the success or failure of meaning negotiations in providing comprehensible input depends on the point in the discourse at which they occur. The authors therefore question a prevailing assumption in the second language acquisition literature that the mere quantity of meaning negotiations within a discourse is an accurate predictor of the quantity of comprehensible input that results. They propose that meaning negotiations should be analysed within a discourse framework to explain their role in creating comprehensible input. 
90-281 Ellis, Rod (Ealing Coll. of Higher Ed). Are classroom and naturalistic acquisition the same? A study of the classroom acquisition of German word order rules. Studies in Second Language Acquisition (Bloomington, Ind), 11, 3 (1989). 305-28.

This article reports a study of the classroom acquisition of German word order rules by adult, successful language learners. Data elicited by an information-gap task performed by 39 learners of L2 German at two points in time are used to describe the sequence of acquisition of three obligatory word order rules. A comparison of this sequence with that reported for naturalistic learners of German revealed no difference, despite the fact that the order in which the rules were introduced and the degree of emphasis given to the rules in the instruction differed from the naturalistic order. The classroom learners, however, did appear to be more successful than the naturalistic learners in that they reached higher levels of acquisition in a shorter period of time. The results of this study support the claim that the classroom and naturalistic L2 acquisition of complex grammatical features such as word order follow similar routes. They also suggest that classroom learners may learn more rapidly. These findings are discussed with reference to both theories of L2 acquisition and language pedagogy.

90-282 Harley, Birgit and King, Mary Lou (Ontario Inst. for Studies in Ed.). Verb lexis in the written compositions of young L2 learners. Studies in Second Language Acquisition (Bloomington, Ind), 11, 4 (1989), 415-39.

The L2 lexical proficiency of 69 grade 6 French immersion students is compared with that of 22 native French-speaking peers, based on verb use in five written compositions. Measures of lexical error, variety, specificity and sophistication show clear differences between the two groups. The learners' patterns of use of verb vocabulary are considered in relation to frequency and utility in French, the degree of congruence between $\mathrm{L} 2$ and $\mathrm{L} 1$, and the morpho-syntactic complexity of some specific types of French verbs. Results are further discussed in relation to observational data from grade $6 \mathrm{im}$ mersion classrooms.

\section{0-283 Hulstijn, Jan H. (Free U., Amsterdam). A comparison between the information-processing and the Analysis/Control approaches to language learning Applied Linguistics (Oxford), 11, 1 (1990), 30-45.}

Two cognitive approaches to first and second language learning are juxtaposed: (1) the information-processing framework, and (2) Bialystok's Analysis/Control framework. It is concluded that, to the extent that both frameworks are descriptive 'metaphors', it is impossible to choose between them on empirical grounds. The main difference between the two appears to be a difference in focus. The Analysis/Control framework seems to be equipped mainly to account for performance differences on metalinguistic tasks, by considering the degree of Analysis of knowledge and the degree of Control of knowledge as independent skill components. It can account only poorly, however, for the initial stages of first and second language acquisition, notwithstanding claims by its proponents. The information-processing framework on the other hand seems especially equipped to account for the construction and reconstruction of both implicit and explicit mental representations of linguistic information, in declarative as well as in procedural form. It provides a parsimonious conceptualisation of the acquisition of primary as well as of secondary (metalinguistic) skills, of both first and second languages.

\section{0-284 Jonz, Jon (East Texas State U.). Textual sequence and second-language comprehension. Language Learning (Ann Arbor, Mich), 39, 2 (1989), 207-49.}

This paper reports research into the interactive roles played in verbal comprehension processes by the sequence of textual elements, text-specific prior knowledge, and levels of language proficiency. Four cloze tests were administered to undergraduate $(n=246)$ and graduate $(n=240)$ native speakers of English and to undergraduate non-native $(n=238)$ speakers at three universities. One test passage was a set of descriptive facts with very little linear connectivity. A second test was based on the 
chronological account of a psychological experiment. The third and fourth tests were scrambled versions of the first two. Prior to the administration of the tests, half of the subjects were allowed to read the entire, intact, sequentially ordered text before completing the cloze test derived from it. For the native speakers who read the simple collection of facts, textual sequence and topic-specific prior knowledge did not contribute significantly to comprehension; however, for all subjects who read the chronological account, variation in the text's naturally occurring sequence and the interaction of that sequencing with the reader's access to topicspecific prior knowledge were important factors in comprehension. Moreover, proficient non-native speakers were significantly more able to capitalise on recently acquired topic-specific prior knowledge, especially when the cloze task that they were given was presented in its normal sequence. These findings are interpreted as evidence of non-native textboundness.

\section{0-285 Koda, Keiko (Ohio U.). The effects of transferred vocabulary knowledge} on the development of L2 reading proficiency. Foreign Language Annals (New York). 22, 6 (1989), 529-40.

This study explored the specific effects of vocabulary knowledge, transferred from a first language, in the development of second language reading proficiency. The study was conducted with 24 college students enrolled in a first-year Japanese programme. Specifically, the study examined the effects of transferred vocabulary knowledge on: (a) the acquisition of L2 linguistic knowledge, (b) verbal processing skills, and $(c)$ reading comprehension. It was found that: (1) L2 vocabulary knowledge was most highly correlated with reading comprehension; (2) that vocabulary knowledge was the single most significant factor differentiating students with related L1 orthographic backgrounds from those with unrelated L1 orthographic backgrounds; and (3) that differences in test performance between the two groups became significantly greater over time. These findings seem to suggest that transferred vocabulary knowledge increases $\mathrm{L} 2$ reading comprehension; moreover, the initial advantage magnifies its effects over time as task complexity increases, thus enhancing the overall development of L2 reading proficiency.

\section{0-286 Loulidi, Rafik. Is language learning really a female business? Modern Languages (London), 76, 4 (1989), 201-8.}

Many studies note a decline (especially among boys) in the popularity of subjects like French and German. Imbalance between the sexes is found not only in secondary but in higher and adult education, and in the teaching profession. Research has shown that boys and girls tend to have different attitudes towards language learning, girls showing significantly more positive attitudes than boys. The differences stem mainly from social and cultural pressures - languages may be seen as 'admirable' for girls but 'unmanly' for boys. Studies show that co-educational language classes have the effect of polarising attitudes: girls' liking for French increased more in mixed than in single-sex schools; boys in single-sex schools made better progress than boys in mixed schools. Provision within a mixed school of single-sex groups for language learning improved the performance of boys (and also of girls), perhaps because both sexes feel less constrained or embarrassed in single-sex groups. The type of teacher behaviour and different teaching methods may affect boys and girls differently.

\section{0-287 Maclntyre, P. D. and Gardner, R. C. (U. of Western Ontario). Anxiety} and second-language learning: toward a theoretical clarification. Language Learning (Ann Arbor. Mich), 39. 2 (1989), 251-75.

Reviews of the literature on foreign-language anxiety show a considerable amount of ambiguity arising from the conflicting results of past studies. This study attempts to show that these difficulties can be resolved given an awareness of the theoretical perspective from which this research has developed. Specifically, it was predicted that anxiety based in the language environment would be associated with language learning whereas other types of anxiety would not show consistent relationships to performance. Eleven anxiety scales were factor analysed yielding two orthogonal dimensions of anxiety which were labelled 'General Anxiety' and 'Communicative Anxiety'. It was found that only Communicative Anxiety is a factor in both the acquisition and production of French vocabulary. 
Analyses of the correlations between the anxiety scales and the measures of achievement show that scales of foreign-language anxiety and state anxiety are associated with performance. Scales of test anxiety, audience sensitivity, trait anxiety, and other types of anxiety did not correlate with any of the production measures. Finally, a model is proposed which describes the development of foreign-language anxiety.

\section{0-288 O'Malley, J. Michael (Georgetown U.) and others. Listening comprehension strategies in second language acquisition. Applied Linguistics (Oxford), 10, 4 (1989), 418-37.}

Listening comprehension is viewed theoretically as an active process in which individuals focus on selected aspects of aural input, construct meaning from passages, and relate what they hear to existing knowledge. This theoretical view has not been sufficiently supported by direct research which clarifies what listeners actually do while engaged in listening tasks. This study focused on the mental processes second language learners use in listening comprehension, the strategies they use in different phases of comprehension, and the differences in strategy use between students designated by their teachers as effective and ineffective listeners. The students in this study were all from Hispanic backgrounds, intermediate in English proficiency, and were enrolled in ESL classes at the secondary level. Data were collected using think-aloud procedures in which students were interrupted during a listening comprehension activity and asked to indicate what they were thinking. Findings indicated that mental processes students use in listening comprehension paralleled three theoreticallyderived phases of the comprehension process: perceptual processing, parsing, and utilisation. Each phase was characterised by active processing and by the use of learning strategies. Three predominant strategies which differentiated effective from ineffective listeners were self-monitoring, elaboration, and inferencing. The findings were related to implications for instructional practice.

90-289 Patkowski, Mark S. (City U. of New York). Age and accent in a second language: a reply to James Emil Flege. Applied Linguistics (Oxford), 11, 1 (1990), 73-89.

This article responds to the arguments raised against the Critical Period Hypothesis (CPH) by James Emil Flege in 'A Critical Period for Learning to Pronounce Foreign Languages?' published in $A p-$ plied Linguistics, 8, 2 (see abstract 88-10). An examination of the relevant literature leads to the conclusion that there is sufficient evidence to support the notion of an age-based limitation on eventual proficiency that can be attained by learners in a second language. It is argued that Flege did not represent the $\mathrm{CPH}$ entirely accurately, and that convincing counter-evidence to the $\mathrm{CPH}$ has not been presented. It is further argued that there is enough evidence to show that child second language acquirers are indeed superior in terms of ultimate ability, so that rejection of the $\mathrm{CPH}$ is unjustified at this time.

\section{0-290 Raphael, Taffy E. and others (Michigan State U.). Students' metacognitive knowledge about writing. Research in the Teaching of English (Urbana, III), 23, 4 (1989), 343-79.}

This study examined fifth and sixth grade students' metacognitive knowledge about the processes of writing narrative and expository texts. Students' declarative, procedural and conditional knowledge was examined using group questionnaires and individual interviews prior to, during, and following participation in four writing programmes, each lasting approximately five months. The programmes emphasised the communicative contexts for writing (stressing task function and communication), knowledge of text structure (and its use during writing), a combination of text structure and communicative context, or neither (a language arts textbook-driven control). Results suggested that creating a communicative context enhances students' awareness of audience and purpose, as well as their understanding of different aspects of the writing process. Text structure instruction enhances students' understanding of the questions that writers answer and of conventions used in expository writing (such as key words and phrases). The combined programme enhanced students' understanding of how such conventions are used as signals to their readers about the purpose of their writing. 
90-291 Rutherford, William E. (U. of Southern California). Preemption and the learning of L2 grammars. Studies in Second Language Acquisition (Bloomington. Ind), 11, 4 (1989), 441-57.

Preemption is a hypothesised process by which an incorrect form in a learner's interlanguage is replaced by a correct one. In first language acquisition, forms that have been created by a productive mechanism but not encountered in input, e.g. breaked, she died him, does he wants it?, are expunged when the input provides a different form with the same meaning; on the other hand, forms which have been met in input are retained even if different and apparently synonymous forms are encountered. In second language acquisition, however, preemption some- times fails to operate, which explains fossilisation and the fact that adults rarely master a new language fully. Reasons for this failure are unknown, but one may be that adults tolerate or expect synonymy more than children. The extent of first language influence requires investigation: for example, are learners more likely to persist with forms such as the destroy of nature, despite exposure to the correct alternative, if their first language lacks derivational morphology?

\section{0-292 Sindermann, Gerda and Horsella, Maria (U. of Chile). Strategy markers in writing. Applied Linguistics (Oxford), 10, 4 (1989), 438-46.}

Strategy markers have been studied by several authors in oral production. In this paper the authors attempt a similar task using written production. Results obtained from the analysis of the written product of adult EFL learners in the science domain are presented. The 'strategy markers' are first identified and listed, then they are analysed to interpret the linguistic difficulty and the strategy used. Finally, a comparison is made between the 'strategy markers' used in oral communication, and those found in writing.

\section{0-293 Thomas, Margaret (Harvard U.). The interpretation of English reflexive} pronouns by non-native speakers. Studies in Second Language Acquisition

(Bloomington, Ind), 11, 3 (1989), 281-303.

\begin{abstract}
Ninety-six second-language learners of English responded to a 30 -item multiple-choice questionnaire requiring them to identify the antecedent of a reflexive pronoun. Their judgements differ from those of a native-speaker control group in that they do not require that a reflexive take a clause mate antecedent, but both groups share a preference for subject over non-subject antecedents. The second-language learners do not seem to transfer first language (L1) grammar into the second
\end{abstract}

language (L2), nor do they recapitulate the course of L1 acquisition. An extension of Wexler and Manzini's (1987) parameter-setting model of L1 acquisition to L2 data may account for some of these results, but the high incidence of long-distance binding of reflexives remains problematic: these second-language learners have set the governing category parameter too widely without positive evidence.

\section{0-294 Tomasello, Michael and Herron, Carol (Emory U.). Feedback for language transfer errors. The Garden Path technique. Studies in Second Language Acquisition (Bloomington, Ind), 11, 4 (1989), 385-95.}

In this study two methods were compared for correcting language transfer errors in the foreign language classroom. Thirty-two English-speaking college students enrolled in two sections of an introductory French course served as subjects. Eight commonly encountered English-to-French transfer errors were identified and randomly assigned to one of two teaching conditions for one class section; each error was assigned to the opposite condition for the other section. In both teaching conditions students began by translating English sentences into
French. The sentences were such that an L1 (first language) transfer strategy produced correct translations (e.g., using savoir for some uses of 'to know'). A sentence for which the transfer would not produce an adequate translation (e.g., a sentence requiring connaitre) was then introduced in one of two ways. In one condition - termed the Garden Path condition-students were given the new sentence and asked to translate as before. Their inevitable transfer error was then immediately corrected by the teacher. In the control condition 
students were simply given the correct French form and told that it differed from the English pattern (they were not given the opportunity to commit a transfer error). Student learning of the nontransferable form was assessed three times through- out the course of the semester, and at all time points performance was better in the Garden Path condition. This finding was interpreted as support for a cognitive comparison model of second language acquisition.

90-295 Üzawa, Kozue and Cumming, Alister. Writing strategies in Japanese as a foreign language: lowering or keeping up the standards. Canadian Modern Language Review (Toronto), 46, 1 (1989), 178-94.

This paper studies the processes of composing in a distinctly foreign language, Japanese for Anglophone Canadians. Analyses of survey, think-aloud, interview, and text data for a small number of adult students suggest that writing in a foreign language involves a dialectic between "keeping up the standard' strategies (associated with mother-tongue composing) and 'lowering the standard' strategies (to access knowledge readily in the foreign language). Implications for instruction centre on ways of prompting 'keep up the standard' strategies to foster learning through composition writing in foreign languages.

90-296 Westphal, Germán. The critical age, individual differences and grammar rules in adult language acquisition. Canadian Modern Language Review (Toronto), 46. 1 (1989), 83-102.

This paper discusses three highly controversial issues in language acquisition, in the light of the theory of principles and parameters: (a) the apparent attrition the LAD undergoes by the age of puberty; $(b)$ some differences observable among second language acquirers; and $(c)$ whether explicit grammar rules can become part of linguistic competence. The answers to these questions can be summarised as follows: the LAD becomes drastically inefficient by the age of puberty because of some internal functional reasons related to its parameter-setting mechanism; child language acquisition involves parameter setting whereas adult language acquisition involves parameter switching; some crucial differences observable among adult language acquirers are due to their LAD's relative ability to switch parameter values depending on their level of exposure to different languages during childhood; conscious knowledge about language cannot become part of linguistic competence because the LAD takes raw linguistic data as input, not linguistic statements about language as such.

\section{Research methods}

\section{0-297 James, Allan R. (U. of Amsterdam). Linguistic theory and second language phonological learning: a perspective and some proposals. Applied Linguistics (Oxford), 10. 4 (1989), 367-81.}

This paper considers the relationship between linguistic theory and the study of L2 phonology and develops a set of criteria by which second-language acquisition researchers may draw on phonological theory for their work and at the same time contribute to phonological theory by their own study. The criteria established in the first part of the paper allow L2 analysts to commit themselves to a particular theory via principled decisions concerning the object and goals of their analysis. It is claimed that given the present state of knowledge, nonlinear generative phonological theories provide the most promising frameworks for L2 study. In the second part of the paper, a short review of the literature on L2 phonological acquisition reveals that such research has not in the past been greatly concerned to define itself in relation to phonological theory. In the third part, concrete proposals are made for a particular model of L2 phonological acquisition, which employs the criteria discussed and adopts elements of non-linear phonological theories in its descriptive apparatus. It is shown, for example, that this type of phonological framework enables significant claims to be made concerning the complex nature and course of development of an L2 phonology in acquisition. 


\title{
Contrastive-error analysis
}

\author{
90-298 Bogacheva, E. M. and Uspensky, М. В. Прием межьязыковых \\ сопоставлений на занятиях по неродному языкя. [Using interlingual comparisons in \\ foreign language teaching.] Русскй язык за рубежсом (Moscow), 5 (1989), 61-6.
}

Comparisons between the native and the target language in the FL classroom have frequently been seen as harmful in that they cause interference and negative transfer. But such comparisons can be very useful in that they serve to eliminate interference rather than reinforce it. Interference itself may be overt or covert. Overt interference is where native speech habits are carried over unconsciously into the target language. Covert interference is where native speech habits (grammatical categories, verbal aspect, phonemic distinctions, etc.) are absent in the target language. Interlingual comparisons serve also to motivate learners and awaken their interest in their native as well as their target languages.

\section{0-299 Nickel, Gerhard (U. of Stuttgart, FRG). Some controversies in present-} day error analysis: 'contrastive' vs. 'non-contrastive' errors. IRAL (Heidelberg, FRG), 27. 4 (1989), 293-305.

In recent years, analyses of error in second-language acquisition have tended to deny or diminish the influence of the learner's mother tongue, and attribute most or all errors to language universals. The author disagrees with this trend, especially as exemplified in Dulay, Burt and Krashen's Language two (1982). He points out that earlier researchers such as Lado never claimed that contrastive analysis could account for all errors, and conversely that the founders of interlanguage theory, Corder and Selinker, never denied that first language influence had a place, whereas Language two takes an extreme position without adequate evidence. Many errors can be explained equally well by contrastive or universalist theories. A proper study of the subject should look at all aspects of learner language, not just the very small set of features concentrated on by researchers interested in universals, and it should take into account differences between secondlanguage and foreign-language contexts, and variables such as teaching methodology, group behaviour, national differences, elicitation techniques, the effects of stress, and hyper-correction.

\section{0-300 Selinker, Larry (U. of Mich). CA/EA/IL: the earliest experimental record.} IRAL (Heidelberg, FRG), 27, 4 (1989), 267-91.

The link between CA/EA and IL revolves around language transfer concerns. A look at the earliest experimental record confirms that studies find both linguistic material derivable from NL (but in a 'selective' way) and 'autonomous' linguistic material, i.e. material that derives neither from NL nor TL. These studies predate the 'IL hypothesis' and thus argue for the reality of learner-generated partially independent systems. They also show that traditional units of linguistic description do not provide the whole interlingual story and that new abstract interlingual units come out of this concern with $\mathrm{CA} / \mathrm{EA} / \mathrm{IL}$ relationships.
The earliest experimental record provides an empirical anchor and an intellectual foundation upon which more recent SLA studies and research stand. Detailed consensus findings are presented. As a result, we can begin to explore the vast $C A$ and EA literature for confirmed insights into the SLA process, linking language transfer concerns (both from NL and other known ILs) with empirical concerns of universal processes. But the evidence presented here suggests that language transfer processes may at times be prime, not the other way around.

\section{0-30 Terry, Robert. The effectiveness of student enquiry skills. Canadian Modern Language Review (Toronto), 46, 1 (1989), 147-63.}

This study on interrogation in French is based on the work of Theodore Kalivoda in Spanish concerning the communicative effectiveness and grammatical accuracy of foreign language students in generating appropriate questions in reaction to situational stimuli presented in English. Although the statistical results of the two studies vary due to the nature of the interrogative systems of French 
and Spanish, students demonstrate similarities in communication errors, especially incorrect interrogative words and structures, verb tenses and persons, and vocabulary usage. This paper discusses the types of errors found in student questions asked in French and potential sources of these errors.

\section{Testing}

\section{0-302 Hamp-Lyons, Liz. Language testing and ethics. Prospect (Adelaide,} Australia), 5, 1 (1989), 7-15.

Language testing has to engage the attention and commitment of a circle wider than testing experts, particularly of teachers, and to be ethical must have no damaging effects on learners and institutions. Tests must discriminate accurately. These requirements are prior to validity and reliability but subsume both and cannot exist without them. The kinds of validity are reviewed and explained (face, criterion, content, construct) as are the subdivisions of criterion validity (predictive and concurrent). Reliability within correlation ranges of 0.85 and 0.95 is a precondition of validity. In addition, tests should have beneficial backwash effects on learning and be as simple, cheap and administratively practical as necessary to secure these benefits. Tests which are expensive to develop and validate may be cheaper in the long run because they will obviate the wastage caused by wrong decisions.
None of these requirements can be traded off against the others, though existing tests often fall down in this respect, e.g. the first version of the British Council/UCLES English Testing Service, which, it is claimed, could be shortened and simplified without loss.

As we have not yet discovered all the constructs and their interrelations in language use and language learning, a language test tends to be simultaneously a test of the individual and of the psychometric model used to construct the test instrument. Writing-proficiency tests, for example, though usually used as an index of language in general, may be testing only a sub-skill quite distinct from other language proficiencies. Classroom teachers should be encouraged to contribute their knowledge to the construct, and not be alienated by the technicalities of testing.

\section{0-303 Kenkel, James M. (U. of Illinois) and Tucker, Richard W. (Bowling} Green State U., OH). Evaluation of institutionalised varieties of English and its implications for placement and pedagogy. World Englishes (Oxford), 8. 2 (1989), 201-14.

Traditionally, ESL programmes in the United States have not distinguished between students coming from countries where English has been institutionalised, such as Nigeria, and those from countries where it has not been, such as Japan. However, the legitimacy of these institutionalised or nativised varieties has become more and more accepted. In spite of this acceptance, scant attention has been focused on how ESL programmes might adapt to the growing consensus. This paper outlines an application of theoretical understandings of nativised varieties to the very practical concerns of ESL programmes, namely, testing, placement and pedagogy. First, through analysis of placement essays written by Nigerian and Sri Lankan students at an American university, it is demonstrated that the non-recognition of the legitimacy of nativised varieties can have the very real effect of lowering a student's placement. A two-tiered evaluation is then suggested which discriminates between those students competent in English but significantly unfamiliar with the American variety and those whose competence in English is deficient. Finally, the authors advance a pedagogical approach and techniques which they believe to be appropriate for speakers who are competent in a non-native variety, but are familiar with the American idiom and culture.

\section{0-304 Williams, K. L. Three new tests for overseas students entering post- graduate and vocational training courses. ELT Journal (Oxford), 44, 1 (1990). $55-65$.}

This article reports the creation and trial of three new exit tests for students (mostly Asian) attending pre-course English language training at the English Preparation Centre (EPC) which is administered by the Commonwealth Department of Employment, Education and Training, Sydney.

The aims of the trial were to bring into operation a testing programme which reflected the EPC 
student population's needs and which satisfied the usual validity criteria. The methods used involved the drawing up of specifications to match students' needs, the analysis and selection of appropriate content, the design of formats and test booklets, pre-testing, administering, and the statistical analysis of results gained over a twelve-month period.

The results were evaluated initially in terms of tutors' and students' responses, and finally in terms of several concurrent validation procedures, and proved highly positive. The conclusion reflected the need for continual revisions to be made to individual test components, and the main recommendation to maintain the testing programme in its entirety has since been accepted by the administration.

\title{
Curriculum planning
}

\section{0-305 Beretta, Alan (Michigan State U.) The programme evaluator: the ESL researcher without portfolio. Applied Linguistics (Oxford), 11, 1 (1990), 1-15.}

A major problem for the ESL programme evaluator is to address the questions that those who commission and hope to use evaluation findings want answered, without relinquishing his claims to academic research standards. This paper elaborates on the nature of the problem, arguing for recognition of the need for an increased dialogue between evaluation and policy analysis. The dangers inherent in such a dialogue are highlighted. Ways of increasing the likelihood that evaluations can actually be utilised are discussed along with suggestions for avoiding the pitfalls. It is concluded that an appeal to a notion of 'disciplined inquiry' is helpful in maintaining academic standards while speaking to real-world concerns.

\section{Course-materials design}

\author{
90-306 Adaskou, K. and others. Design decisions on the cultural content of a \\ secondary English course for Morocco. ELT Journal (Oxford), 44, 1 (1990), 3-10.
}

This paper discusses the choices made in a large-scale textbook project concerning the cultural content of the new English course for Moroccan secondary schools. The authors look first at the different meanings of 'culture' in foreign-language teaching; at the possible arguments for including a foreign cultural component in an English course designed for a national market in a non-anglophone country; and at the means of conveying this cultural component. The paper then suggests an idealised procedure for deciding on the cultural content of a course, and goes on to apply this procedure to the Moroccan case, outlining the solutions adopted. In conclusion, it is suggested that what should really determine these choices is not the top-down strategy that has been presented, but rather the prevailing attitude towards the foreign culture among teachers of English. In the authors' opinion, it is teachers' attitudes to a language textbook that most of all determine its effectiveness and its useful life-span.

\section{0-307 Puhl, C. A. and Swartz, J. J. Designing a second-language bridging course for university students. Per Linguam (Stellenbosch. South Africa), 5, 1 (1989), 17-32.}

The increasing number of students, especially black students, enrolling at university and needing to study in a medium of instruction which is not their mother tongue, has underlined the need for additional language preparation as one way to reduce the failure and dropout rate. A possible solution is a bridging course aimed at developing academic language competencies to enable students to cope with the communicative demands of their chosen course.

An effective bridging course must take into account the requirements of the chosen institution and course, the level of student competency already achieved, and the actual student needs. These needs are divided into three areas: cognitive, which includes communicative macro-language skills and problem-solving skills; affective, which includes self-confidence, acceptance of responsibility, and motivation; and behavioural, which includes crosscultural competencies.

Issues include duration of the course, the extent to which the course caters for special purposes, and the didactic strategies employed. Three further considerations are the influence on the course of sponsors from business and industry, the academic level of the course, and effective evaluation methods. 
90-308 Robinson, Peter J. A rich view of lexical competence. ELT Journal (Oxford), 43, 4 (1989), 274-82.

This article begins by examining some features of the negotiation of meaning between learners and teachers, where the goal of the interaction is to convey the meaning of a technical word from the teacher to a learner. It is useful to distinguish between the declarative knowledge 'that' words have particular meanings, and the procedures typically employed for realising or 'achieving' this declarative knowledge. These procedures form part of our 'procedural' knowledge of 'how' to negotiate. A communicative view of the interactive nature of lexical negotiation requires that we focus as much on procedures as we do on the more narrowly defined declarative meanings which specialist words have. This requires us to take a 'richer' view of what is involved in lexical competence than that which many vocabulary learning materials seem to be based on. The author's proposal is to adopt Canale and Swain's (1980) checklist of the dimensions of communicative competence; exercise types are presented which exemplify how these dimensions could be covered lexically.

\section{0-309 Smith, D. and others. English language and orientation: the SFU Indonesian Project. Canadian Modern Language Review (Toronto), 46, 1 (1989). 164-77.}

This paper describes the English language support provided for Indonesian graduate students studying at a Canadian university. Special features of the programme are discussed: the use of two instructors in a team-teaching arrangement, extended planning time, and a curriculum focused upon the students' specialised academic needs. Recommendations for future similar programmes include: (1) maintaining use of more than one instructor, (2) focusing English study around academic interests, (3) providing students with a foundational course in their area of academic endeavour at the same time as their English orientation classes, (4) reducing the amount of hours students spend in English instruction, and (5) scheduling tutoring time so that students get ongoing English instruction and not just editing services.

\section{Teaching methods}

\section{0-310 Alexander, Louis G. Grammar and English language-teaching today. Der fremdsprachliche Unterricht (Stuttgart, FRG), 96 (1989), 11-15.}

In addition to communicative competence, it is necessary to acquire grammatical competence. Grammar is the support system for communication, but it is important that a balance be achieved between grammar and communication. Grammar explanations must be appropriate to the context in which they are being given, in terms of level of student, length, and purpose. They should also take into account the most common errors made by students. The article concludes with a grammar questionnaire for teachers of English as a foreign language.

\section{0-311 Atkinson, David (Christ Church Coll. of Higher Ed., Canterbury). 'Humanistic' approaches in the adult classroom: an affective reaction. ELT Journal (Oxford), 43, 4 (1989), 268-73.}

The implementation of a humanistic approach in the classroom is a more problematic and controversial enterprise than is often suggested. The tone of much that is 'humanistic' tends to imply a false dichotomy between bright new humanistic classes and boring traditional ones. There is a danger that the teacher will come to see part of his or her role as enabling learners to become 'better', 'wholer' people. Some humanistic writers make extravagant claims about the learning process and dismiss more structured language teaching out of hand. In extreme cases, self-exploration threatens to take priority over language learning, and other inappropriate objectives are given prominence, such as practising 'the vocabulary of feelings'. Many of the proponents of humanistic activities, believing that successful language learning involves deep, affective investment by learners in the learning experience, advocate techniques which require learners to take part in unorthodox activities (like revealing deep emotions or touching one another) which many of them might find uncomfortable, 
stressful, and highly suspect as language teaching techniques. More allowance should be made for sociocultural and individual diversity. Some cultures find such intrusive techniques unacceptable. Affective factors ought not to be regarded as ends in themselves, and a humanistic approach should not be treated, even implicitly, as some sort of greater good over and above the more 'pedestrian ' business of learning and teaching a foreign language.

\section{0-312 Coste, Daniel (U. of Geneva). Brouillon de lectures. [A rough draft on reading.] Etudes de Linguistique Appliquée (Paris), 76 (1989), 39-48.}

The advent of the word-processor has changed the act of reading in several important respects. The distinction between reader and writer is blurred, as one must do some writing (or equivalent) to call up a text, and can then sometimes re-write it oneself. The distinction between rough draft and final copy is also reduced: a text is always finished and yet never finished, because even the first draft is a 'fair copy', and even the last can be easily amended. Data networks provide potentially unlimited access for readers and writers, but with attendant problems of authentication. The temporary nature of on-screen text can cause anxieties, e.g. about lost data. The screen also 'homogenises' reading in some ways, reducing everything to one standard-size page at a time. But the use of on-screen 'windows' may foster a more flexible, interactive approach.

It is too early to predict the effect of all this on reading habits and skills throughout the population.

\section{0-313 Bacon, Susan M. (U. of Cincinnati). Listening for real in the foreign-} language classroom. Foreign Language Annals (New York), 22, 6 (1989), 543-51.

Authentic reading and listening texts expose students to real language from the beginning of their language study. Although authentic reading texts are available for novice students, real listening traditionally has been delayed until students are at the intermediate or advanced levels. This paper argues that novices can understand and benefit from authentic texts and that an early exposure to such texts will help them develop useful listening strategies for more complex tasks later on. Prelistening strategies are as delicate as pre-reading activities, however. Care must be taken that the text is culturally relevant to the experience of the listener.

\section{0-314 Brown, Gillian. Cultural values: the interpretation of discourse. ELT Journal (Oxford), 44, 1 (1990), 11-17}

It is sometimes suggested that the main problem in understanding discourse in a foreign language comes from not knowing enough about the cultural background in which the language is used. The solution then seems to be to teach as many facts as possible about the cultural background. It is argued here that it is more useful to teach explicit strategies for making inferences from the language used so that knowledge about the cultural background can be gradually constructed in the same way that native speakers of the language gradually construct their knowledge of their own culture.

\section{0-315 Chappelle, Carol and Misuono, Suesue (lowa State U.). Students'} strategies with learner-controlled CALL. CALICO Journal (Provo, Utah), 7, 2 (1989), 25-47.

One of the problematic aspects of computer-assisted language learning (CALL) concerns the degree of learner control in CALL activities. It is generally assumed that students apply certain essential strategies when learning a second language. These are resourcing (requesting help), practice, self-monitoring (checking and editing), self-management (selecting the type of material to work on), and selfevaluation (assessing one's own learning and learning needs).
Foreign students at Iowa State University were tested on grammar areas, e.g. subject-verb agreement, to see to what extent the five learning strategies were used when they were working with a computer. The students' backgrounds and motivation varied considerably, but all were mature university-level adults. It was discovered that some students used some of the strategies some of the time. Taking into account variables such as student motivation, which may have affected the results, it 
is recommended that close observation of students' use of CALL be carried out, especially when they are engaged in practice and self-evaluation.

\section{0-316 Dubin, Fraida. The odd couple: reading and vocabulary. ELT Journal} (Oxford), 43. 4 (1989), 283-7

This article explores the tensions between reading and vocabulary instruction through the metaphor of the odd couple: two unique individuals whose characteristics are quite disparate yet who find themselves living together. While there are mutual benefits from the arrangement of cohabitation, nevertheless the two unavoidably clash with each other. Reading and vocabulary are just such an odd couple. Reading instruction methods for inter- mediate and advanced levels encourage students of a second language to cope with unedited texts. But the lexicon in authentic selections includes so many new words that students can feel frustrated. Still, the demands of the two must be accommodated. With the teacher who makes use of unedited reading selections particularly in mind, the article offers suggestions for facilitating the successful meshing of reading and vocabulary skill practice.

\section{0-317 Gayle, Grace M. H. In furtherance of second language teaching style. Canadian Modern Language Review (Toronto), 45, 4 (1989), 631-40.}

This paper defines second language teaching styles as specific configurations of teacher/student behaviours during the teaching episode. These behaviours are described in terms of categories of a number of dimensions of teaching which are not independent. Since styles (configurations) described previously have contributed to the explanation of a significant portion of the variance in learning and since they have proven capable of differentiating teachers in the same programme, or using the same method, they are regarded as useful conceptual tools. An attempt is made to identify additional components and dimensions of style which have not yet been discussed. The nature and complexity of style is considered at three major levels of significant experience which are themselves distinct but inseparable.

\section{0-318 Hinz, Klaus. Grammatikunterricht unter besonderer Berücksichtigung} leistungsschwacher Schüler. [Grammar teaching with special reference to lowattaining pupils.] Praxis des neusprachlichen Unterrichts (Dortmund, FRG), 4 (1989), 365-74.

In the light of previous studies of the characteristics of pupils with learning difficulties, various ideas are put forward for teaching the bare essentials of grammar. A distinction is made between what the pupils will need to use actively and know passively. A deductive learning process is preferred, in which the teacher draws attention to rules as examples occur in practice. An example is given of the way grammar might be presented in printed form. This would proceed in short steps, each grammatical point being illustrated with a situative minitext and wherever possible visually. The situation should be explained in the mother tongue and the core phrase translated. Secondly, pragmatic rules for use, not an explanation of the system, should be given. Finally, instructions for the formation of grammatical structures should be presented in tabular form. Further examples are given of the way that pupils can be taken step by step from an initial stage where they only have to confirm or deny the correctness of sentences used by the teacher, to the point where they can produce their own sentences, and of exercises aimed at motivating pupils to internalise the grammatical structure by means of 'prompting' and 'fading' (providing, then withdrawing, assistance).

\section{0-319 Hirvela, Alan (Chinese U. of Hong Kong). Five bad reasons why language teachers avoid literature. British Journal of Language Teaching, 27, 3 (1989), 127-32.}

Although, from a theoretical point of view, literature is staging a modest come-back, few practitioners are actually teaching it. The prevailing point of view is highly pragmatic, not looking beyond the practical needs of learners. Five reasons are cited as representing the core of resistance to 
literature (leaving aside theoretical questions relating to appropriateness).

(1) A fundamental misconception among language teachers concerning the term 'literature', which they take to imply 'inaccessible' and archaic language too difficult for learners to understand, e.g. Dickens, Mallarmé. Only standard texts are assumed to be 'literature'. Such a limited concept of literature springs from the fact that many language teachers received much of their own education in a traditional university department in which the literary canon formed the foundation of their studies. They are too indoctrinated to give equal consideration to popular forms such as science fiction or detective stories, which are readily available for language-teaching purposes. Many language teachers do not read anything of a literary kind (which is surprising and disturbing) so they are unlikely to instil a love of literature in their students. (3) Many language teachers place a heavy reliance on the 'materials' approach, which is convenient but very restricted. (4) Teaching literary texts involves a certain amount of work: ready-prepared materials will have greater appeal for the inexperienced teacher. Yet the preparation for literature-based teaching enhances the teacher's understanding of the text and provides variety. (5) Teacher-training programmes do not train teachers to work with literary texts, nor do books dealing with course and curriculum design.

\section{0-320 Lehmann, Denis and Pelfrène, Arnaud (Crédif, ENS de Fontenay-} Saint-Cloud). Ordinateur et socialisation dans la classe de langue. [Computers and socialisation in the language classroom.] Etudes de Linguistique Appliquée (Paris). 76 (1989), 19-37.

A computer database called Lecticiel is being used to teach reading skills. It can give information on a group of texts, e.g. which ones were written before a certain date or on a certain subject, and on an individual text, e.g. number of nouns or verbs, frequency and contexts of a specific word, typographical features. When learners use it, it also keeps records of the operations they choose and can suggest alternatives.

The envisaged use in class is not 'programmed learning' but the very opposite: individualised, learner-directed work, with the computer available as a resource in a corner of the room, normally used for a few minutes at a time to complement work on paper texts. A four-phase approach is suggested: at first all learners work on the same text in different ways, then on the same text in their own way, then on different texts ('co-operative autonomy'), and finally, though still helped by group discussion, all learners develop their own approach, which can be transferred to their reading after the course unaided by machine.

\section{0-321 McCrory, D. P. (Richmond Coll.). On teaching foreign literature: a reply to L. R. Barrett. British Journal of Language Teaching, 27, 3 (1989), 124-6.}

This article takes issue with the argument put forward in the same journal by L. R. Barrett (see abstract 89-335), namely that the best approach to studying a foreign language text in class is to first quickly read the text in an English translation. The teacher then alerts students to major themes/topics, after which they read the original text. Barrett prefers this to the laborious line-by-line translation method, which frustrates the keen learner.

This article argues that there are other major problems connected with teaching literature which have not been addressed. There are still important texts in Spanish, Italian and German for which no translation exists. In American courses there is no time for line-by-line translation. The main problem lies in a system which promotes literary appreciation and analysis at the expense of relevant work in studying the spoken language, and acquiring necessary communicative competence. Let pupils read for enjoyment what their contemporaries abroad are reading, not classics of literature. The best solution to the problem of teaching foreign literature is for traditional objectives to be changed, so that the time presently given to literary studies is used to strengthen and promote 'real' language work. 
90-322 Nünning, Ansgar. Schülerzentrierter Fremdsprachenunterricht und das Problem der Textauswahl. Überlegungen und Vorschläge zu einer Erweiterung des Lektürekanons im Englischunterricht der Oberstufe. [Pupil-centred foreign language teaching and the problem of choice of text.] Die Neueren Sprachen (Frankfurt am Main, FRG) 85. 6 (1989), 606-19.

Based on the 'uniformity of reading materials in English for the advanced level' as a theory which continues to apply, the author discusses criteria to be used in selecting suitable texts and argues in favour of including contemporary literature as a means of overcoming the established practice of reading certain works as canon. Since many narrative texts in contemporary English literature are eminently suitable for treatment in the teaching of English for didactic, literary and target-group-specific reasons, but have been relatively unknown in Germany so far, a few contemporary prose authors are introduced with commentary. The article concludes with a few considerations with a view to intensifying the co-operation between literary criticism and literary didactics in the light of teaching literature.

\section{0-323 Parke, Tim (Hatfield Poly.). Grammar and unity in language awareness. British Journal of Language Teaching, 27, 3 (1989), 159-62.}

The case for focusing in any approach to language teaching and learning on variety and differentiation in languages, and on the flexibility that may exist between forms and meanings, is rejected in this article. It is essential to draw attention to what is shared as well as what is different in languages. A successful language policy for English and Bengali speakers, for example, would seek to integrate the language communities, through comparison of sounds, grammar, morphology, lexis, and the different conventions of reading and writing. In the case of grammar, there are surface differences, but basically the same relations are expressed.

90-324 Porcher, Louis (U. de la Sorbonne-Nouvelle). La diagonale du lecteur. [The reader's diagonal.] Etudes de Linguistique Appliquée (Paris), 76 (1989), 9-18.

Five different types of reading are defined and the role of new technologies in relation to them is considered. They are: reading for pleasure, reading to acquire culture (for visible social benefit), 'academic' reading (in order to pass examinations), 'consumer' reading (signs, posters, TV, etc.), and 'professional' reading (in connection with one's work). Because readers in the last category read not linearly, but skimming for information, it is here that technology plays the greatest role-e.g. in producing works of reference. [A brief reference to the effect of this kind of reading on foreignlanguage learning is made.] In conclusion, it is thought that reading classical books for pleasure will certainly not disappear, but will become an esoteric activity.

\section{0-325 Ralph, Edwin G. (U. of Saskatchewan, Canada). Research on effective teaching: how can it help L2 teachers motivate the unmotivated learner? Canadian Modern Language Review (Toronto, Ontario), 46, 1 (1989), 135-46.}

Effective teachers create a classroom climate that is positive and productive: students' morale (and often their achievement) increases when they feel accepted by the teacher and their peers. Good teachers are able to vary their leadership style according to the situation to create a friendly and businesslike atmosphere. This helps students with negative attitudes, whatever their past record of low achievement may have been.

Managerial strategies carried out by the teacher on meeting new students include (1) planning class rules and procedures, (2) implementing them in a reasonable way and (3) establishing authority early. Maintenance strategies include (i) reviewing rules and procedures, (ii) maintaining reinforcement and pointing out consequences, and (iii) handling inappropriate conduct firmly and calmly.

As far as the subject-matter content is concerned, instructional strategies involve $(a)$ planning lessons and units, $(b)$ presenting clear lessons, $(c)$ providing for student success and challenge, (d) maintaining momentum and smoothness, and (e) incorporating variety, creativity and humour. 
90-326 Savage, J. Fiona. Teacher non-verbal behaviour in an adult immigrant beginners' class. Prospect (Adelaide, Australia), 5, 1 (1989), 38-45.

An experienced ESL teacher was observed with a class of 18 adult beginners, aged 20 to $50+$ from several different countries. A video recording was made and 24 different types of non-verbal behaviour comprising four categories (head, trunk, ambulatory and vocalisation) were noted. Coding sheets were prepared and the frequency of each behaviour recorded. Head behaviours occurred more often than other kinds. The teacher's verbal behaviour was excluded from the study; student response was not monitored. Further research, taking class level and students' origins into account, is indicated.

\section{0-327 Underhill, Adrian. Process in humanistic education. ELT Journal (Oxford), 43, 4 (1989), 250-60.}

The overriding emphasis in humanistic approaches to language learning is on the notion of process, which holds the needs and experience of the learner to be paramount. The teacher's role is primarily that of a facilitator, initiating negotiation and feedback and thereby encouraging learners to take responsibility for their own work. The need for reflection and, equally, the need to make mistakes are valued as important aspects of the learning process. The teacher's sensitivity is crucial in maintaining the appropriate balance between autonomous and auth- oritative power. The genuineness, unconditional acceptance, and empathy which characterise a good facilitator focus the emphasis on process over task in learning.

Whilst there is awareness of the difficulties both teachers and learners may face in managing change towards humanistic attitudes, there must be recognition that more effective learning lies not in any innovative technique, but in a shift at the level of awareness and attention to process. 